\title{
Los cuerpos académicos como espacios para la formación y producción de conocimiento. Experiencias, narrativas, saberes y tensiones
}

\section{Academic bodies as spaces for the formation and production of knowledge. Experiences, narratives, knowledge and tensions}

\author{
David Pérez Arenas, ${ }^{*}$ Pedro Atilano Morales, ${ }^{* *}$ Jesús Francisco Condés Infante, ${ }^{* * *}$ \\ Javier Hernández Morales****
}

Recibido: 28 de mayo de 2020 Aceptado: 1 de septiembre de 2020 Publicado: 30 de septiembre de 2020

To cite this article: Pérez Arenas, D., Atilano, P., Condés, J. F. y Hernández, J. (2020). Los cuerpos académicos como espacios para la formación y producción de conocimiento. Experiencias, narrativas, saberes y tensiones. Márgenes, Revista de Educación de la Universidad de Málaga, 1 (3), 355-381

DOI: https://doi.org/10.24310/mgnmar.v1i3.9400

\section{RESUMEN}

El trabajo que presentamos tiene el propósito de recuperar las experiencias y saberes que como grupo de investigación, integrado a través de lo que en México se denomina Cuerpo Académico (CA), adquirimos en relación con el trabajo de investigación colegiado desarrollado durante diez años, en una institución donde hasta antes de 2010, este se realizaba más de manera individual.

Las aportaciones se derivan del desarrollo de varios proyectos que elaboramos relacionados con la formación para la investigación en los posgrados en Educación en México, los cuales se apoyaron en la narrativa para recuperar, a través de entrevistas, las experiencias y saberes que como tutores de estos programas acumularon sobre la metodología y didáctica de la investigación educativa.

Como docentes investigadores y a una década de la conformación de los primeros CA `s en el Instituto Superior de Ciencias de la Educación del Estado de México (ISCEEM), consideramos importante sistematizar, reflexionar y compartir nuestras trayectorias, experiencias y saberes en torno a los procesos de formación colegiados, así como los problemas y tensiones institucionales, colectivas y personales que enfrentamos tanto en los procesos de generación de conocimiento como en la formación de investigadores.

El escrito se divide en dos partes: en la primera damos cuenta del contexto, propósitos e importancia de los CA para las Instituciones de Educación Superior en México (IES), después presentamos una breve descripción de nuestro Cuerpo Académico "Formación para la investigación y eficiencia terminal en los posgrados en educación”, cerramos con los referentes teóricos metodológicos que sustentan nuestras narrativas, integradas en la segunda parte, en las que compartimos las experiencias y saberes en relación con el trabajo colegiado, los problemas que enfrentamos, la manera en que los hemos sorteado, así como su importancia para nuestra formación académica y desarrollo profesional.

Palabras clave: cuerpos académicos; formación investigación; narrativas; tensiones

"David Pérez Arenas 0000-0001-5653-0332 ISCEEM, (México) pearenas62@gmail.com
**Pedro Atilano Morales 0000-0001-7745-8421 ISCEEM, (México) atila1268@yahoo.com.mx
${ }^{* * *}$ Jesús Francisco Condés Infante ISCEEM, (México)
${ }^{* * * z}$ Javier Hernández Morales 0000-0001-7631-9876 ISCEEM, (México) hmoralesjavier@hotmail.com 


\section{ABSTRACT}

The paper that we present has the purpose of recovering the experiences and knowledge that as research group, integrated through what in Mexico is called the Academic Body (AB), we acquired in relation to the collegiate research work developed over ten years, in an institution where until before 2010, this was done more individually.

The contributions are derived from the development of several projects that we elaborated related to training for research in postgraduate studies in Education in Mexico, which relied on the narrative to recover through interviews, the experiences and knowledge that as tutors of these programs accumulated on the methodology and didactics of educational research.

As research teachers and a decade after the formation of the first AC in the Higher Education Sciences of the State of Mexico, we consider it important to systematize reflect and share our trajectories, experiences and knowledge around the processes of collegiate training, as well the problems and institutional, collective and personal tensions that we face both in training of researchers.

The writing is divided into two parts: in the first we give an account of the context, purposes and importance of the $\mathrm{AB}$ for Higher Education Institutions in Mexico, then we present a brief description of our Academic Body "Training for research and efficiency terminal in postgraduate education", we close with the theoretical methodological references that support our narratives, integrated in the second part, in which we share experiences and knowledge in relation to collegiate work, the problems we face, the way in which the we have raffled as well as its importance to our academic training and professional development.

Keywords: academic bodies, research training; narratives; tensions

\section{INTRODUCCIÓN}

Los Cuerpos Académicos (CA) son un programa que surgió en México con el propósito de apoyar, estimular y promover las actividades de docencia, investigación, tutoría y gestión académica que desarrollan los docentes e investigadores de las Instituciones de Educación Superior (IES), inicialmente enfocado a las universidades y años después extensivo a los tecnológicos y escuelas formadoras de docentes, lo que ha representado una oportunidad de mejora para nuestro trabajo académico.

Sin embargo, la manera en que los académicos nos hemos incorporado a los CA, realizamos las actividades requeridas y obtenemos los productos demandados, han sido muy diversas y desiguales, debido tanto a la heterogeneidad de contextos y condiciones institucionales en que se ha desarrollado este programa, como a la manera en que los sujetos las hemos asumido en nuestros centros de trabajo.

De manera que, a una década de integrar los primeros CA en el Instituto Superior de Ciencias de la Educación del Estado de México ISCEEM, nuestro centro laboral, es necesario hacer una valoración de la importancia y posibilidades que estos grupos de trabajo han generado para el desarrollo institucional y la trayectoria profesional del personal académico del Instituto. Una institución que tiene entre sus objetivos, la producción y difusión de conocimiento; apoyar la formación y actualización del magisterio a través de programas de posgrado, como el Doctorado en Ciencias de la Educación, la Maestría en Investigación de la Educación y algunas especializaciones; además de desarrollar las funciones de difusión y extensión.

Con base en lo anterior, definimos el propósito de este trabajo: analizar la importancia de los CA como espacios de formación y para la producción de conocimiento colegiado, a partir de las experiencias y saberes de los integrantes de uno de los primeros CA del ISCEEM en obtener su re- 
gistro formal ante la Secretaría de Educación Pública (SEP), enfatizando tanto las problemáticas y tensiones enfrentadas como las posibilidades que nos han ofrecido los proyectos y actividades desarrolladas; utilizando la narrativa como estrategia metodológica.

Partiremos de algunos referentes contextuales en relación con el propósito de los CA en instituciones como el ISCEEM y con los particulares del que formamos parte "Formación para la Investigación y Eficiencia Terminal en los Posgrados en Educación”, para después hacer algunas precisiones teóricas en torno a las categorías analíticas que articulan este escrito: experiencias, saberes y tensiones, así como algunos apuntes metodológicos sobre la narrativa como estrategia de investigación.

La segunda parte del documento estará integrada por las narrativas de los cuatro integrantes del CA, en las que desde diferentes lugares, compartimos la manera en cómo nos hemos integrado al trabajo colegiado, los problemas que hemos enfrentado y cómo los hemos sorteado, así como la importancia que este ha tenido para nuestra formación académica y desarrollo profesional.

\section{PRIMERA PARTE: REFERENTES CONTEXTUALES, TEÓRICOS Y METODOLÓGICOS}

\subsection{Profesionalización del personal académico y de la investigación a través de los cuerpos académicos}

Ante las dinámicas de un mundo cada vez más complejo y particularmente de los constantes cambios, exigencias y necesidades en el ámbito educativo, desde la última década del siglo pasado, en México surgieron políticas que han vuelto la mirada a las IES con la intención de vincular docencia e investigación para la producción y generación de conocimiento, coadyuvando al mismo tiempo la actualización y profesionalización de su personal académico.

De acuerdo con (Ortega, C. y Hernández, A., 2016), el vínculo docencia-investigación en las últimas décadas, se convirtió en una política encaminada a favorecer la producción del conocimiento para elevar la calidad educativa. De ahí deriva la creación de programas orientados a fortalecer los procesos de profesionalización y actualización de los profesores de tiempo completo (PTC) con funciones de docencia, tutoría e investigación, como el Programa de Mejoramiento del Profesorado (Promep) de las IES, creado en 1996, actualmente Programa para el Desarrollo Profesional Docente (Prodep).

Una de las acciones emprendidas en este programa fue la promoción de CA, inicialmente dirigidos sólo a las universidades públicas e institutos tecnológicos, fue hasta 2009 cuando se hicieron extensivos a las instituciones formadoras de docentes: las escuelas normales, para las que se han definido como “... grupos de profesores/as de tiempo completo que comparten una o varias Líneas de Generación o Aplicación Innovadora del Conocimiento (investigación o estudio), en temas disciplinares o multidisciplinares del ámbito educativo, con énfasis especial en la formación de docentes, así como un conjunto de objetivos y metas académicas comunes...” (SEP, 2020); con el propósito de equilibrar las funciones sustantivas de docencia, investigación y gestión.

En 2010 estos programas se ampliaron al ISCEEM, donde la investigación se promovía interdisciplinariamente por líneas de investigación y campos de conocimiento, sin embargo, su 
desarrollo era más por proyectos individuales, por lo que el trabajo colegiado organizado con un reconocimiento y registro formal se inició con tres CA que obtuvieron su registro en este año como "Cuerpos Académicos en Formación”, entre ellos, el nuestro.

El Promep, a veinte años de haber surgido, extendió su cobertura a 730 IES en el país, 260 escuelas normales, 16 ubicadas en el Estado de México, además del ISCEEM. De 2010 a enero de 2020, en el Instituto se han registrado siete CA, de los cuales tres mantienen su registro en formación, uno está en consolidación y dos se han desintegrado.

La trayectoria de los CA en el Instituto ha estado permeada por condiciones que han limitado los procesos de producción y generación de conocimiento colegiado, entre ellos encontramos al menos tres: a) cargas excesivas de trabajo docente en los programas de maestría, doctorado o especialidad; b) desplazamiento de la investigación como función sustantiva del personal académico del instituto, y c) mayor preocupación por el control y la administración de las funciones sustantivas que por la promoción del trabajo académico y la producción de conocimiento. Todo ello ha limitado la incorporación de los CA a redes académicas, problema que comparten también los cuerpos académicos consolidados de las universidades.

No obstante, la trayectoria de cada se ha caracterizado por generar nuevas formas de trabajo y producción de conocimiento que han incidido de diferente manera en el campo de la investigación educativa en que se ubican, en la atención de las problemáticas del sistema educativo y en la formación de estudiantes de posgrado mediante la tutoría y su graduación; trabajo condensado y difundido a través de la publicación de ponencias, artículos, capítulos de libros y libros colectivos, así como de su participación en eventos académicos nacionales e internacionales, donde han compartido su producción y experiencias.

\subsection{El cuerpo académico: formación para la investigación y eficiencia terminal en los posgrados en educación}

De manera oficial obtuvimos nuestro registro como CA en Formación, el 18 de noviembre de 2010, en la Área de Educación, Humanidades y Arte, en la Disciplina de Docencia e investigación, con dos Líneas de Generación y Aplicación Innovadora(s) del Conocimiento (LGAC): Currículum e Institución Escolar, y Formación para la Investigación; la primera con el propósito de analizar y comprender la relación que se establece entre la estructura y organización curricular de un plan de estudios, los procesos y prácticas educativas orientadas a la formación para la investigación en el posgrado; la segunda para sistematizar las experiencias que investigadores de posgrados habían acumulado en cuanto a la metodología y didáctica de la investigación educativa. De manera inicial, el equipo se formó con David Pérez Arenas (coordinador) Pedro Atilano Morales, y Francisco Condés Infante (+); en 2014 se integró Javier Hernández Morales, adscritos a la Sede Toluca y diferentes Divisiones Académicas del Instituto. ${ }^{1}$

1 El ISCEEM está organizado en una sede, ubicada en Toluca, capital del Estado de México, y cinco Divisiones Académicas, en Ecatepec, Chalco, Tejupilco, Nextlalpan y Jocotitlán respectivamente. 
En 2011 registramos y obtuvimos financiamiento para desarrollar el proyecto "Perfiles, Trayectorias, Experiencias y Saberes en relación con la Formación para la Investigación y la eficiencia Terminal en los Posgrados en Educación”. El 7 de noviembre de 2016, después de haber participado en dos procesos de evaluación, el CA fue dictaminado favorablemente para ser reconocido como en Consolidación; en 2019 nos sometimos a evaluación para promovernos al nivel Consolidado y estamos en espera de resultados.

Derivado del primer proyecto, además de varias ponencias y artículos previos, en 2017 publicamos el libro "Formación para la investigación en los posgrados en educación. Perfiles, trayectorias, experiencias y saberes” (Pérez, D., Morales, P. y Condés, F.); trabajos que hemos presentado en diferentes foros, congresos, coloquios y encuentros académicos, como el Congreso Nacional de Estudios de Posgrado en 2018 y el XV Congreso Nacional de Investigación Educativa (2019).

En mayo de 2015, registramos el proyecto "Experiencias y saberes sobre metodología y didáctica de la investigación de los académicos en los posgrados en educación”, como producto de ello, está en revisión un nuevo libro para su publicación, además de otras ponencias y artículos.

Nuestros perfiles, trayectorias y experiencias, en el terreno académico son diversas, pero antes de integrarnos al CA habíamos coincidido en comisiones de diseño y evaluación del plan de estudios de la maestría del ISCEEM, en el seminario de Currículum e Innovación Educativa, en algunos comités tutoriales, pero sobre todo, en nuestro compromiso con el Instituto y el gusto por la investigación.

Nuestra formación académica inicial es distinta: un pedagogo, un antropólogo y dos educadores, esto ha favorecido la construcción de la mirada sobre el objeto, no sólo en las posiciones teóricas, sino también en las epistémicas y metodológicas. Los cuatro tenemos una antigüedad que va de los 25 a 35 años de servicio en el sistema educativo, nuestras experiencias profesionales inicialmente fueron en educación básica, pero el mayor tiempo ha transcurrido en el posgrado, como investigadores, docentes, tutores, directores de tesis, gestores, coordinadores de una división académica, integrantes de algún órgano o comisión institucional relacionada con nuestro objeto de estudio, lo que nos ha permitido enriquecer nuestra mirada para el análisis del ejercicio de la investigación y la formación de investigadores.

Con excepción de Condés (+), los otros tres integrantes del CA seguimos laborando en el ISCEEM. Además de las líneas de investigación del CA, desarrollamos proyectos en las de Educación, sociedad y cultura, Javier Morales, Práctica educativa Pedro Atilano, Filosofía y teoría educativa David Pérez, a partir de estudios relacionados con los procesos curriculares en educación media superior y posgrado, tutoría en secundaria y media superior, escuelas primarias multigrado y los sustentos teórico-epistémicos del campo educativo.

Todos los integrantes contamos con el Perfil Deseable del Prodep, reconocimiento que se otorga al personal de tiempo completo que labora en IES que cuenta con estudios de posgrado y cumple con estándares en relación con su productividad en docencia, tutoría y gestión académica; el líder pertenece al Sistema Nacional de Investigadores y es integrante del Consejo Mexicano de Investigación Educativa; los cuatro colaboramos con la Red Mexicana de Investigadores de la Investigación Educativa y con la Red de Posgrados en Educación, A. C; hemos participado en 
diferentes eventos académicos para difundir los resultados de los proyectos, así como para dialogar con otros investigadores en relación con los avances, resultados y problemas enfrentados.

Nuestros perfiles y trayectorias nos han permitido reconocernos en y con el objeto de estudio, así como en las formas de acercarnos y construirlo. Nuestras diferencias, más que generar fracturas o complicaciones, han enriquecido y condensado el trabajo colegiado desde la diversidad y la multirreferencialidad.

\subsection{Referentes teórico-metodológicos: experiencias, saberes, tensiones y narrativas}

El trabajo a través de un CA es en sí mismo ya toda una experiencia, que ha implicado la articulación de nuestros distintos perfiles, conocimientos, saberes e historias, en el desarrollo de un proyecto o propósito determinado; como lo menciona Zemelman (1987), somos los sujetos sociales quienes otorgamos un sentido y significado particular derivado de las condensaciones de los tiempos, contextos sociales y culturales en que nos desarrollamos, al tiempo que alimentamos la construcción de opciones de futuro diferentes.

De manera que cuando nos proponemos hacer un recuento y análisis de nuestras experiencias como integrantes de un CA, nos proponemos dar cuenta de las actividades que de manera individual o colectiva han modificado nuestras concepciones y prácticas educativas e institucionales, en relación con la producción de conocimiento y la formación para la investigación de manera colegiada; en este sentido, nos interesa dar cuenta de la manera en que eso que nos pasa, no depende exclusivamente de nosotros mismos, ni de lo que nos pasa sino de la manera en como habitamos o vivimos esa experiencia.

La experiencia significa algo que no depende de nosotros, dentro de lo que Larrosa (1998) llama principio de exterioridad, dice, para empezar la experiencia es “eso que me pasa”, algo que no es una proyección de mí mismo, que no es el resultado de mis ideas y que no depende de mí saber, ni de mi poder; por lo que el eje temático de la experiencia que habita al sujeto y lo hace un sujeto de experiencia, es uno mismo.

Así, comprendemos las experiencias como portadoras y generadoras de un conjunto de saberes, que orientan o modifican a la vez las prácticas y concepciones educativas de quienes las adquirimos y acumulamos a través de lo que Tardif (2009) ha denominado saberes experienciales o existenciales que permiten reconocer a los maestros; nosotros agregaremos a los investigadores como sujetos que no sólo pensamos y actuamos con la cabeza (dimensión cognitiva), sino también a partir de la articulación de diferentes registros asociados con otras dimensiones: éticas, políticas y culturales.

Los saberes, surgen como una categoría que se opone a los denominados conocimientos científicos, teóricos o cognitivos y académicos, sustentados en un paradigma explicativo o empírico analítico; para en su lugar reconocer los conocimientos derivados de las experiencias, las vivencias, las historias y creencias personales, es decir, los denominados saberes cotidianos, experienciales y prácticos de los sujetos.

Como integrantes del CA, en nueve años de trabajo hemos documentado, analizado y publicado este tipo de experiencias y saberes asociados con la formación para la investigación por 
medio de los proyectos desarrollados, pero consideramos que como docentes, investigadores y tutores hemos adquirido también y acumulado otros tantos asociados con lo que implica el trabajo colegiado, el objeto de estudio y líneas generadoras de conocimiento del cuerpo académico: la formación para la investigación.

Estas experiencias y saberes están mediados por las tensiones que el trabajo colegiado y la formación para la investigación enfrentan o producen en los posgrados en educación, debido a la dificultad de articular de manera coherente los elementos, factores o condiciones asociados con las dimensiones sociales e institucionales, con las particulares y subjetivas que intervienen en dichos procesos.

La categoría de tensiones la retomamos de Laclau (2006), quien señala que esta se genera cada que coexisten dos o más elementos que son necesarios en una relación o proceso, pero que son incompatibles entre sí, "esto significa que donde hay una tensión entre el elemento diferencial y el elemento equivalencial, esta tensión no puede ser superada sino a través de maneras deformadas de representación; esto es, hay tensión siempre que dos elementos necesarios no pueden cristalizar en una relación de articulación positiva entre ambos (Laclau, 2006, en De Alba, 2017, p. 296).

Como lo veremos más adelante en la formación para la investigación son muy comunes las tensiones que se generan, cuando por un lado desde la dimensión institucional, dentro de sus propósitos, se establece como prioritario la producción del conocimiento y el trabajo colegiado, pero sus estrategias se sustentan en una lógica de control académico administrativo, intentando por todos los medios hacer una equivalencia entre ambos principios, el resultado es siempre catastrófico. Estas son algunas de las razones que nos hicieron tomar la decisión de sistematizar y analizar las experiencias, saberes y tensiones que como integrantes de un CA habíamos adquirido y acumulado, pero no compartido, con el propósito de dar cuenta no sólo de la manera en que, consideramos, las dinámicas institucionales han sobredeterminado (Althusser, 1967) el trabajo colegiado, sino también de la forma en que este ha incidido en la vida institucional y en nuestros propios procesos de formación; para lo cual nos apoyamos en lo que Lyotard (1993) considera como la mejor estrategia para dar cuenta de este tipo de saberes: la narrativa.

El argumento en que se sustenta Lyotard para afirmar lo anterior, es que el saber utilizado en los actos del habla no se reduce a derivado de la ciencia ni a los conocimientos contenidos en las teorías orientados a describir los objetos o explicarlos con un sentido denotativo o descriptivo, como los derivados de la lógica racional y científica, propia de la Modernidad, desde la cual se intenta silenciar, rechazar o negar otro tipo de saberes provenientes de otros ámbitos como la vida cotidiana, que tienen tanta o en algunos casos más importancia que los denominados por la ciencia, pues pueden armonizar más con la costumbre y la cultura de una comunidad.

De manera que si bien, el saber científico se formula a través de las disciplinas, las teorías o los axiomas que las estructuran, el saber narrativo se formula y expresa a través del relato, y la narrativa es el medio a través del cual podemos recuperarlo y analizarlo.

En este sentido, la naturaleza de nuestro objeto de estudio y el propósito planteado nos demandó recuperar aspectos significativos de las trayectorias académicas y profesionales de los 
tutores del posgrado, a partir de sus relatos y narrativas que nos compartieron, y ahora nosotros retomamos, para lo cual seguimos algunas rutas que se centraron en la narrativa, metodología relacionada con las historias de vida, autobiografías, relatos de vida y trayectorias profesionales.

En nuestras investigaciones trabajamos las narrativas, como las concibe Chase (2015), historias cortas cuando se refieren a un acontecimiento particular, historias extensas cuando abordan un aspecto significativo de nuestra vida o una narrativa completa cuando se relata desde el nacimiento hasta el presente. No optamos por éstas últimas, sino por las historias cortas que nos permitieran compartir algunos aspectos de nuestros "relatos de vida" profesional o "narrativa personal”, los cuales se centraron en aspectos significativos sobre el ejercicio y formación para la investigación, enfatizando el trabajo colegiado, la producción de conocimiento y la formación de investigadores.

Los autores que nos brindaron los argumentos para comprender los relatos de vida profesional fueron Ricoeur (1995) y Lyotard (1993) quienes asocian la narrativa con la costumbre, la cultura de una comunidad, a un saber hacer, aun saber ético y sensitivo que se configura temporalmente. Por su parte, autores como (Bolivar, A., Domingo, J. y Fernández, M, 2001), nos permitieron comprender la narrativa como la cualidad estructurada de la experiencia entendida y vista como un relato, a partir de acciones temporales personales, por medio de la descripción y análisis de los datos biográficos, es una particular reconstrucción de la experiencia, por lo que, mediante un proceso reflexivo, se da significado a lo sucedió o vivido (Ricoeur, 1995).

Medina (2000) apoyada en Huberman, Thompson y Weiland, (2000), Serrano y Ramos (2011), nos permitió reconocer las posibilidades que tienen las narrativas, en la modalidad de trayectorias profesionales como una manera de estudiar y conocer nuestra vida profesional, a partir del trabajo colegiado orientado a la producción de conocimiento.

Para la formación para la investigación, otro de los referentes teóricos en nuestros estudios, nos apoyamos en autores como Moreno (2010), quien señala que esta tiene que ver con el acceso a la cultura de producción de conocimiento en una disciplina determinada y en Sánchez Puentes (2010), quien la comprende como el conjunto de acciones orientadas a favorecer la apropiación y desarrollo de los conocimientos, habilidades y actitudes necesarias para el desempeño de actividades asociadas a la producción de conocimiento.

Por nuestra parte, entendemos la formación para la investigación como el conjunto de concepciones y dispositivos que se generan y ponen en juego para que una persona o grupo se apropie de un capital académico-cultural; y desarrolle una serie de habilidades, destrezas y competencias propias del oficio de la investigación, con el propósito de producir conocimiento original o aplicar el existente para atender las problemáticas sociales y disciplinarias de un campo en particular (Pérez, D., Atilano, P. y Condés, F. 2017 p. 29).

Fue a partir de estos referentes teóricos y metodológicos como iniciamos la aventura formativa que contribuyó a la construcción de la mirada para la investigación y elaboración de nuestras narrativas. 


\section{SEGUNDA PARTE: NARRATIVAS EN TORNO AL TRABAJO COLEGIADO}

\subsection{Qué cosa fuera, si fuera de otra manera}

Jesús Francisco Condés Infante $(+)$

Y no hay en América, ni tal vez en el planeta, país de mayor profundidad humana que México y sus hombres. A través de sus aciertos luminosos, como a través de sus errores gigantescos, se ve la misma cadena de grandiosa generosidad, de vitalidad profunda, de inagotable historia, de germinación inacabable.

Pablo Neruda... "Confieso que he vivido".

El contenido de este escrito da cuenta de mi experiencia como integrante del Cuerpo Académico "Formación para la investigación y eficiencia terminal en los posgrados en educación”, en el ISCEEM. Lo que presento es el producto de mi propia intersubjetividad y su exposición es el resultado de mi percepción en relación con lo que he vivido desde mediados de 2010, tiempo en que se formó dicho cuerpo académico. Tengo que aclarar que estoy adscrito a la Sede Toluca del ISCEEM, ya que algunos pormenores expuestos más adelante podrán ser razonados con más precisión considerando este dato.

El contexto: a poco más de 27 años de pertenecer al ISCEEM, he estado consciente de que el Instituto no cuenta con las condiciones más favorables para realizar la tarea de la investigación educativa, a pesar de ser una institución que entre sus prioridades menciona este objetivo; las carencias se dejan ver en algunos aspectos: no tiene un presupuesto ex profeso para financiar esa tarea; su acervo bibliográfico es muy pobre si consideramos la extensa cantidad de publicaciones que se han hecho sobre el campo educativo en los últimos diez años, durante los que no se han destinado recursos para este rubro, no se tiene suscripción a revistas periódicas especializadas, y el poco material que llega a ingresar es por donación.

Considero que la situación es bastante grave, pues a pesar de que en los últimos años ha crecido la infraestructura física, los espacios de trabajo no son los más apropiados para el desempeño académico; el esquema administrativo no es el más conveniente para las labores que se realizan, se ha priorizado el control en lugar de flexibilizar los procesos como apoyo al trabajo académico; el servicio del área de informática hace un gran esfuerzo por dar un buen servicio, sin embargo, hay muchas cosas por hacer, como actualizar y dotar de nuevos equipos más eficientes, sobre todo en las divisiones académicas donde las condiciones son más precarias, aún más si reconocemos que las tecnologías de la información y la comunicación se han convertido en un servicio de primera necesidad. Soy consciente de estas condiciones poco favorables (aunque las cosas no siempre fueron así), sin embargo, estoy convencido de que el factor humano es lo más importante, y en este sentido, tengo la certeza de que aun en la adversidad institucional se pueden hacer cosas importantes. Estas líneas tienen el propósito de dar cuenta de ello a partir de mi incorporación al CA al que pertenezco.

El inicio: en este contexto, y ante la invitación de David Pérez, acepté formar parte del cuerpo académico, en otro tiempo ya había tenido la oportunidad de trabajar con él, la experiencia 
había sido bastante favorable y halagüeña. El equipo se integró también con Pedro Atilano, con quien también había colaborado, lo que nos daba la convicción de que "se podía trabajar bien"; posteriormente, se integró con nosotros Javier Hernández.

Al inicio fue importante sentarnos a dialogar y de alguna manera definir el tema a investigar y el sustento teórico y metodológico que le íbamos a dar al trabajo, exponiendo nuestras inquietudes y puntos de vista. Fue fundamental también escucharnos y llegar a los consensos y acuerdos en torno a la dinámica de trabajo, los tiempos y las tareas que cada uno tendríamos que hacer para que las reuniones fueran ágiles, productivas y avanzáramos en el proyecto.

El diálogo académico: cuando se trata de realizar trabajo en equipo y de forma colaborativa, este punto es imprescindible, sobre todo porque en el equipo se conjugaron distintas formaciones profesionales, trayectorias académicas, historias de vida e intereses personales, inclusive distintos estilos de trabajo. Este diálogo e interacción, en lo personal fueron muy significativos, ya que me permitieron romper con el aislamiento académico con el que se solía trabajar de manera individual en la frialdad del cubículo -en un instituto de por sí ya frío, sobre todo en el invierno-, donde uno se las tiene que arreglar por cuenta propia. El diálogo, sobre todo el académico, no se dio por casualidad, fue una estrategia de trabajo que se fue nutriendo con el tiempo; es decir, es una construcción que requiere de la voluntad y la participación de todos los integrantes del equipo. La posibilidad del diálogo me ha permitido realizar la investigación de manera compartida y más dinámica, lo que ha resultado bastante grato y satisfactorio.

Sobre la organización: sin duda, establecer acuerdos en un equipo de trabajo -sobre todo cuando pensamos que nos abriga un espíritu democrático- puede ser complicado, genera conflictos, resistencias y tensiones entre los integrantes; sin embargo, tengo la certeza de que ese no ha sido nuestro caso. Considero que la posibilidad y la libertad con la que hemos trabajado, nos han dado la oportunidad de tomar la palabra y escucharnos, cuando ha sido necesario, lo cual ha hecho que la atmósfera de trabajo sea cordial y amigable, sin perder la jerarquía y la función que cada uno hemos asumido. Aquí ha intervenido un factor determinante, que es la capacidad de liderazgo asumida por el compañero David Pérez. Estoy convencido de que tanto en una institución como en un equipo de trabajo y organización de un cuerpo académico, el liderazgo que impere será determinante. David ha sido el orquestador de la organización del CA, siempre con nuevas propuestas, con ideas para el trabajo y con una actitud democrática y propositiva. Dicho lo anterior, he podido adaptarme a los tiempos, las necesidades y compromisos que hemos asumido en estos años de trabajo.

El reconocimiento: en el ambiente académico, al menos en el campo de la investigación educativa, en mi apreciación subjetiva y personal, en los últimos años ha imperado una lógica por la hegemonía del poder, que en los hechos se traduce en la pertenecía a grupos ya consolidados en instituciones con un cierto reconocimiento y que trae como resultado una especie de exclusión para los que no pertenecemos a tales grupos. Al interior del CA y como investigadores educativos y sujetos sociales, más bien ha imperado la ética del reconocimiento, es decir, más allá de nuestras cualidades y deficiencias -esto lo digo por mí-, he sentido el reconocimiento de parte de los demás integrantes del CA, es decir, ha sido grata la valoración que he tenido y me han mostrado todos los compañeros del equipo. En este punto, quiero destacar que, infortunadamente, no sucede lo mismo con la dinámica institucional, pues no se muestra ningún tipo de reconocimiento, 
toda vez que de manera inédita, el CA está en el nivel de en consolidación. La ética del reconocimiento ha posibilitado un ambiente cordial para el trabajo tanto de manera individual como colectiva. Aprovecho este espacio para hacer un reconocimiento a mis compañeros del CA por sus tiempos y conocimientos compartidos, pero sobre todo, por su gentileza, su compañerismo y su espíritu de colaboración.

Sobre la formación: con el correr de los años -de mis años-, en mi quehacer profesional, me di cuenta de que estaba cayendo en una especie de estancamiento y apatía por el trabajo académico, claro, siempre cumpliendo con la responsabilidad asumida. Dicho sea de paso, no es que en el ISCEEM impere la costumbre de dialogar con las ideas, debatir en foros, presentar avances de investigación, cuando esto se logra es más bien a título personal o gracias a pequeños grupos de trabajo que sin duda, afortunadamente, existen. Me atrevo a decir que más bien impera un individualismo académico donde cada uno vela por sus intereses y necesidades. Mi desempeño en el CA ha representado una oportunidad para "sacudirme", para generar ideas, desafiar nuevos temas y metodologías de investigación y crear discursos novedosos -al menos el propio-. El trabajo en el CA ha tenido sus variaciones, en tiempos de más o menos actividad; también me ha permitido renovar y accionar mi espíritu de trabajo y el gusto por la vida académica, lo cual considero importante para mi formación profesional: leer estudios originales, atreverme a producir textos académicos, pero sobre todo, como diría Kant, aventurarme a pensar. Tengo la creencia de que el pensar y la razón son fundamentales para la formación académica.

Más allá de la frontera de la academia: en este punto quiero destacar un asunto que considero vital: me refiero a la vivencia cotidiana en el equipo. Cuando he tenido la oportunidad de asistir a eventos académicos o reuniones de trabajo de otras instituciones, veo que se guarda cierta formalidad, es decir, parece que esta característica es más importante que el asunto que los convoca. Si bien la pertenencia al CA nos requiere para el trabajo académico, en este caso hemos podido trascender dicha "camisa de fuerza" para crear lazos de amistad, lo que ha favorecido un ambiente cordial y amigable, por supuesto, distinguiendo cuando hay que trabajar y cuando se puede convivir. El intercambio académico ha traído como resultado la producción de un libro, otro que está en puerta y un buen número de ponencias publicadas en memoria de eventos académicos a los que hemos asistido.

Por otra parte, la convivencia cotidiana ha acrecentado la confianza, el compañerismo y la camaradería, por medio de muestras de solidaridad, empatía, respeto, admiración y reconocimiento, entre algunos otros elementos. Solo por citar algunos ejemplos, nos hemos acompañado en ver crecer y desarrollar a nuestros hijos - preocupación que sin duda compartimos-, en la despedida de algunos de nuestros seres queridos en su "viaje sin regreso". Han sido largas y provechosas las charlas amenizadas con la degustación de algún vino tinto, hablando de libros, literatura, cine, la familia, reflexiones existenciales, compartiendo nuestros malestares y preocupaciones, tristezas y alegrías. Esta experiencia es lo que, en lo personal, me permite afirmar que el CA es un verdadero equipo de trabajo, yo diría que consolidado -más allá de la clasificación hecha por el Prodep-. Toda esta experiencia, fruto de la convivencia con los compañeros, ha posibilitado que mi estancia haya sido y siga siendo cordial, lo cual he disfrutado y a veces también sufrido; por supuesto que también he de reconocer a otros queridos compañeros y amigos del Instituto que también han aportado para hacerme grata la estancia cotidiana en mi espacio laboral. 
Sobre el tema que nos ocupa: la formación para la investigación es un tema que, junto con el cuerpo académico, he tenido en la mirilla de la investigación casi por una década, pero en el que he estado involucrado desde que trabajo en el ISCEEM, hace poco más de 27 años. Tengo que reconocer que con el paso del tiempo, todos en el equipo hemos podido tener en la mira el tema que desde un principio nos convocó, el recorrido también nos ha abierto otras posibilidades de lectura y de abordaje. Son dos asuntos particulares los que me resultan de interés para reflexionar y seguir investigando: el primero tiene que ver con el papel tanto del tutor como de los comités tutoriales. Recientemente, tuve la oportunidad de asistir a dos exámenes profesionales, uno de la licenciatura en Física, en la Facultad de Ciencias de la UNAM, y otro de maestría en Antropología Física, en la Escuela Nacional de Antropología e Historia. En ambos casos me sorprendió sobremanera la actitud asumida por los tutores principales, mostrando la corresponsabilidad que tienen en la terminación de las tesis; se asumen como una especie de coautores de los trabajos, reconociendo los logros y las carencias cuando los demás integrantes del sínodo intentan cuestionar injustificadamente o intimidar al sustentante.

En la experiencia que tengo como director -ahora se le nombra tutor- de tesis de maestría, he reconocido que, como tal, soy responsable, al igual que el tesista, de la calidad de los trabajos. Traigo a cuenta el tema porque considero que este no es el común denominador a nivel de licenciatura y posgrado, por supuesto me atrevo a decir que no es lo que sucede en el ISCEEM, con sus muy honrosas excepciones. Me parece que el asunto no es de menor importancia. El otro aspecto tiene que ver con el tipo de alumnos que ahora ingresan a los posgrados, particularmente en el Instituto, que es de donde tengo más información porque además estoy involucrado; los intereses académicos y personales, así como las edades, las trayectorias académicas y profesionales de los alumnos son muy diversificadas. Quiero llamar la atención sobre todo en los intereses académicos que tienen los alumnos al ingresar a un programa de posgrado en Educación. Hay que recordar que nuestros alumnos son profesores, en su mayoría, de educación básica y media superior, algunos con cargos directivos, por lo que las expectativas de su formación no siempre concuerdan con las de los académicos ni de los tutores, lo que ocasiona fuertes tensiones y a veces serios conflictos; en fin, estas tendencias hacen que el tema sea relevante, pertinente y necesario de estudiar.

Palabras finales: lo que escribió Neruda en los años cuarenta al describir al México de entonces parece que sigue vigente; ahora creo que se avizoran tiempos mejores en este México que me ha tocado vivir, con sus aciertos y sus errores. Me considero un trabajador de la educación que nunca ha perdido la esperanza. Tengo la convicción de que la pertenencia a este cuerpo académico es una oportunidad de contribuir de alguna manera a crear un México más justo, incluyente y democrático. Y si alguien escribe la historia del ISCEEM, es posible que el cuerpo académico ya tenga un lugar en esa historia.

\subsection{El cuerpo académico. Narrativa de una experiencia de formación}

Javier Hernández Morales

Formar parte del Cuerpo Académico "Formación para la Investigación y la Eficiencia Terminal en los Posgrados en Educación”, a partir de mi incorporación en 2014, ha implicado retos, tensiones 
y aprendizajes, pero al mismo tiempo posibilidades de innovar mi tarea de investigar, todo ello ha derivado en una manera diferente de vivir y mirar esta responsabilidad académica, gracias a la participación en los diversos proyectos de investigación, eventos y encuentros derivados del trabajo en el CA. En este apartado recupero, mediante mi narrativa, los haceres y quehaceres como acontecimientos y sucesos, en tanto vicisitudes como una impronta profesional marcada por la experiencia construida a partir de sucesos y acontecimientos que entretejidos nos conforman como sujetos y nos sitúan en un lugar dentro de la realidad; a partir de un proceso de formación continuo y permanente de encuentros y desencuentros que constituyen nuestra subjetividad (Yuren, 2005), todo ello a partir del tiempo que llevo participando con un grupo de colegas, de quienes he aprendido y, al mismo tiempo, prolongado la mirada en la insoslayable tarea de investigar.

\subsubsection{Incorporación al cuerpo académico como un proyecto profesional}

El ISCEEM, como institución de educación superior, tiene la necesidad de profesionalizar su planta académica a través de diplomados, formación en programas de posgrado, participación en redes y CA; algo que en la última década ha motivado la inquietud de algunos académicos del instituto, tiene que ver con su participación en programas de estímulo profesional a través de la evaluación del trabajo realizado, como es el Prodep y el Sistema Nacional de Investigadores (SNI). Actualmente, en el instituto, algunos académicos forman parte de estos programas.

Mi participación en el grupo responde a la invitación realizada por los colegas cuando culminé el programa de doctorado en Ciencias de la Educación, con el propósito de nutrir los trabajos derivados del proyecto de investigación e incorporar académicos de otras divisiones. Cuando me incorporé, habían concluido el proyecto con financiamiento iniciado en 2011. Mi colaboración en ese momento fue de apoyo en la revisión técnica y editorial, como actividad previa a la dictaminación del libro, tareas que me dieron la oportunidad de integrarme académicamente y entender lo que implicaba pertenecer a un CA como ese.

Mi trabajo más formal se dio a partir del segundo proyecto que desarrollamos entre 2015 y 2017, referido a las experiencias y saberes sobre metodología y didáctica de la investigación, en el que cada uno trabajó una etapa de la investigación (problematización, uso de la teoría, análisis y sistematización de la información, y redacción del informe final), a partir de las experiencias y saberes construidos por los académicos en la tutoría y asesoramiento de trabajos de investigación, así como en el desarrollo de sus propios proyectos.

La participación en los proyectos, tareas y eventos como parte de los trabajos del CA, han permitido fortalecer mis experiencias y saberes relacionados con la investigación y la práctica profesional en el posgrado, lo que ha implicado un compromiso ético con los compañeros para corresponder a la oportunidad brindada, compartiendo con ellos y el Instituto, a través de un posgrado público, un espacio académico de investigación y formación para formar, actualizar y profesionalizar al magisterio del estado; fomentar y desarrollar investigación educativa (ISCEEM, 2011).

Este compromiso no se deriva sólo de una construcción individual, reconozco el profesionalismo que los colegas han mostrado; desde mi llegada al CA me di cuenta de su responsabilidad 
y entrega con cada una de las tareas que realizaban. Por eso, el proyecto profesional que asumí se fincó en el compromiso por corresponder a los compañeros que me dieron la oportunidad de participar en este espacio de formación y aprendizaje, así como con todo lo que el ISCEEM me brinda para desempeñarme profesionalmente y que ha influido en la innovación de mi quehacer académico cotidiano.

De manera, que pertenecer a este CA tiene implicaciones que van más allá del desarrollo de investigación para generar y difundir conocimiento; es identificarse con un proyecto profesional donde emergen y se entretejen subjetividades que también nos conforman a quienes estamos dedicados a la investigación y a la formación de profesionales de la educación.

\subsubsection{Tensiones y retos ante una nueva experiencia de investigación y formación}

Formar parte del CA, desde el principio, representó una oportunidad de encarar mi tarea profesional dentro del Instituto desde otros horizontes. Si bien al incorporarme contaba con el grado de Doctor en Ciencias de la Educación y una experiencia académica de 11 años en el ISCEEM, el trabajo en este colectivo representó un nuevo reto nada fácil de enfrentar en los primeros momentos.

Me convencí de que implicaría un proceso de adaptación en el que había necesidad de distribuir tiempos destinados para atender tanto las funciones sustantivas del Instituto (docencia, investigación y, difusión y extensión) así como las que el CA demandaba (reuniones, tareas, investigación, asistencia a eventos, por mencionar algunas). Reconozco también que este proceso de adaptación implicó conectarme y empaparme de lo que en ese momento los compañeros estaban trabajando, ¡no fue fácil!, pues si bien la temática de la formación para la investigación y la eficiencia terminal en los posgrados no era ajena a mi quehacer profesional, no había tenido la oportunidad de trabajarla como objeto de estudio de un proyecto; mi campo de investigación se había movido en las escuelas multigrado de educación básica en contextos rurales.

Las primeras reuniones de trabajo fueron complicadas, en el sentido de tener que adentrarme en las discusiones en aras de aportar para la construcción y toma de acuerdos. Por eso, a la distancia, veo que mi presencia en esos tiempos obedecía más a la escucha y apropiación de lo que ahí se discutía y construía, no obstante, esto siempre me motivó a la disposición por emprender una nueva experiencia, que hasta el día de hoy me ha dado muchos aprendizajes.

El tránsito vivido como proceso de adaptación a los trabajos del CA ha representado una experiencia construida por prácticas de investigación que de igual manera, son una oportunidad de formación, la cual entiendo como un proceso de desestabilidad en búsqueda de un equilibrio que da lugar a experiencias formativas, que el sujeto construye a partir de momentos de equilibrios y desequilibrios, tal y como lo plantea Yuren (2005). De ahí que incursionar en un nuevo proyecto de investigación, desde el primer momento, implicó reconocerme en mis limitaciones para después documentarme y apropiarme de referentes teóricos a través de lecturas constantes que me permitieran prolongar la mirada en torno a los procesos de formación e investigación en el posgrado.

Del mismo modo, he tenido la oportunidad de nutrir y compartir experiencias y saberes con los colegas en torno a temas de investigación, los cuales he puesto en marcha durante el acom- 
pañamiento y tutoría para la elaboración de las tesis de grado de los estudiantes, así como en la participación de comités tutoriales en los programas de maestría y doctorado, como espacios de diálogo y reflexión de la investigación que los estudiantes llevan a cabo. Por ello, veo que la producción del CA ha tenido incidencias en la formación para la investigación de los estudiantes y tesistas a quienes acompañamos en los posgrados del Instituto.

Otra experiencia de formación tiene que ver con la participación en diferentes eventos y encuentros con otros CA, donde hemos tenido la oportunidad de compartir experiencias y saberes construidos como equipo. Esto también nos ha fortalecido porque permite prolongar nuestra mirada en relación con los procesos de investigación llevados a cabo por otros colegas, al tiempo que vemos la manera en que los conforman desde sus condiciones institucionales.

Una de mis inquietudes en este proceso de formación, caracterizado por los momentos de desequilibrios como tensiones ya compartidas, tiene que ver con la exigencia personal para lograr la obtención del Reconocimiento a Profesores de Tiempo Completo con Perfil Deseable por dos razones: la primera, porque es un criterio considerado en las reglas de operación del Prodep para quienes participamos en algún CA y la segunda, porque los compañeros ya contaban con este reconocimiento, lo cual implicaba un compromiso personal e institucional; por ello, a partir de la convocatoria de 2016, decidí participar, por fortuna logré obtenerlo. Este reconocimiento ha implicado una exigencia profesional, sobre todo en lo que a la producción derivada de la investigación y docencia se refiere, al tiempo que he podido articular mis tareas académicas con las del CA.

\subsubsection{El tránsito a la línea de investigación y generación de conocimiento del CA}

Un asunto presente en esta experiencia está relacionado con la articulación disciplinaria de las líneas y campos de generación de conocimiento. Mencioné ya, que antes de mi incorporación al CA cursé el doctorado en el ISCEEM, donde desarrollé un proyecto de investigación ubicado en la línea de Educación, Sociedad y Cultura y en el campo de conocimiento Educación, Cultura y Diversidad Cultural, desde donde venía trabajando y dirigiendo tesis con temas relacionados a la escuela multigrado, maestros e infancias en el contexto rural.

Debido a las tareas que el proyecto del CA demandaba, tuve que dejar pendiente la continuidad de la investigación del doctorado; no obstante, en mi relación tutorial con los estudiantes de maestría, no me he alejado de lo rural, la escuela multigrado y los sujetos que la hacen posible. Continúo acompañando trabajos de investigación sobre las temáticas relacionadas con los referentes que he construido en mi trayectoria antes y durante del doctorado; del mismo modo, mi participación en los diferentes congresos, se sigue dando en la línea y campo de investigación mencionados. Esto ha requerido procurar un equilibrio entre mi capital teórico en un campo de conocimiento específico y lo que el CA me posibilita a partir de un proyecto relacionado con la formación para la investigación en los posgrados.

Actualmente, en el CA convergen líneas de generación de conocimiento derivadas de los intereses académicos de quienes formamos parte de este espacio de trabajo, pero de alguna manera nos hemos articulado interdisciplinarmente con el proyecto de las experiencias y saberes sobre metodología y didáctica de la investigación en los posgrados, que recién hemos concluido. Por 
ello, un cuerpo académico es una comunidad científica donde se produce y aplica conocimiento, además de innovar a través de una o varias líneas de generación de conocimiento.

De ahí, el proyecto y la temática que nos articulan, se han fortalecido a partir de las líneas de investigación trabajadas por cada uno de nosotros, si bien contamos con referentes distintos, hemos logrado condensar las tareas en un proyecto común que tiene por eje trasversal la formación para la investigación y la eficiencia terminal en los posgrados en Educación.

\subsubsection{Los horizontes del Cuerpo Académico}

Por ahora, he dado cuenta del trayecto en la experiencia de formación que ha implicado pertenecer a este CA al compartir las crisis, movimientos y tensiones que me han permitido construir aprendizajes a partir de nuevas maneras de mirar y llevar a cabo la investigación; apropiándome de saberes en la interacción cotidiana con mis colegas y los de otras instituciones; no descarto las tensiones vividas como momentos de desequilibrio que me han hecho posible dibujar un camino en un espacio académico en el que también me he formado.

Considero que nuestro CA poco a poco ha construido una trayectoria importante a partir de las múltiples tareas derivadas en cada uno de los proyectos que hemos culminado. Es importante mencionar que también hemos logrado consolidar una línea de investigación, a partir de la exigencia académica ante las metas propuestas en los proyectos desarrollados, así como de los factores provenientes de las dinámicas y condiciones institucionales que han incidido significativamente en nuestro quehacer profesional.

La experiencia construida durante este tiempo me permite avizorar horizontes donde el CA se fortalezca mediante la continuidad de nuestros proyectos, así como de la consolidación de nuestras líneas de investigación. Aún existe la necesidad de prolongar nuestros intercambios con otros CA que nos permitan formar parte de redes académicas para la producción de conocimiento científico asociado a la formación para la investigación.

\subsection{Caminar en dirección de la formación. Experiencias en el desarrollo de un cuerpo académico del ISCEEM}

Pedro Atilano Morales

Esta narrativa tiene el propósito de exponer algunas experiencias formativas que se gestaron al momento de integrar y desarrollar un cuerpo académico en el Instituto Superior de Ciencias de la Educación del Estado de México.

En el CA hemos construido proyectos, desarrollado investigaciones, enfrentado retos, fomentado habilidades y experimentado preocupaciones, desvelos, angustias y satisfacciones, entre otras vivencias, que nos han resultado formativas a sus integrantes. Los procesos de formación y construcción de conocimiento que vivimos, como lo señala Zemelman (2009), no devienen sólo con inteligencia o con información, también construimos con deseo, expectativa, imaginación, intuición y voluntad. Por otro lado, este mismo autor plantea la noción de camino y la necesidad de avanzar 
para encontrarse; en este sentido, viví al CA como una posibilidad de encuentro, de construcción de conciencia y de asumir responsabilidades sobre los sucesos del pasado y del presente.

En esta narrativa expongo dos apartados: el cambio de marcos teórico-metodológicos en el desarrollo del CA y algunos desplazamientos significativos en mi proceso formativo.

\subsubsection{Del camino andado a la exploración de nuevos marcos teórico-metodológicos. Trazando el sendero}

La investigación es una de las funciones sustantivas del ISCEEM que se organiza y desarrolla a través de líneas de investigación. ${ }^{2}$ Tradicionalmente, sus académicos se adscriben a una de las líneas para realizar sus proyectos de manera individual, de forma esporádica se desarrollaban experiencias en colectivo. Fue hasta el año 2010 cuando se crearon los CA para desarrollar investigaciones bajo esta nueva modalidad, con la intención de participar de los beneficios que el Promep ofrecía en ese tiempo.

En mi caso, era uno de los académicos que había desarrollado proyectos individualmente en la línea de investigación de Práctica Educativa desde mi incorporación al ISCEEM en 1995, en la División Académica Tejupilco, donde estuve adscrito hasta el año 2010; los objetos construidos estaban relacionados con el estudio de los profesores, sus prácticas y saberes docentes en el nivel básico, en especial de escuelas multigrado. ${ }^{3}$ Colaborar con el CA implicó incursionar en un nuevo campo de investigación, cambiar de tema, la aventura ahora sería construir objetos de estudio referidos a la formación para la investigación, un cambio radical que impactó en la conformación de nuevos marcos referenciales, teóricos y metodológicos.

Los referentes teóricos que habían apoyado mis investigaciones previas a la integración del CA se relacionaban con la vida cotidiana, práctica educativa, saberes docentes y cultura escolar de profesores en escuelas multigrado; los autores trabajados eran Heller, Rockwell, Mercado, Piña, Acchilli, Medina, Fierro, Fortoul, Rosas, Uc Mas, Salgueiro, Tardif, Bustos, Ezpeleta, Fuenlabrada, Weiss y Mcewan; Viñao, Julia y Geertz. Metodológicamente, me apoyaba en enfoques cualitativos, como la etnografía, con Woods, Rockwell y Bertely; y en la investigación-acción con autores como Elliot, Carr, Kemis, Lewin y Latorre.

En tanto objeto de estudio del CA, tenía como propósito sistematizar las experiencias y saberes acumulados por los académicos del posgrado, lo que demandó referentes teóricos planteados por Sánchez Puentes, Arredondo, Moreno, Pérez y Durán sobre los estudios en el posgrado; y de referentes metodológicos asociados con lo biográfico, la narrativa, los relatos y trayectorias profesionales con autores como Ricoeur, Bolívar, Medina, Huberman Michel, Charles L. Thompson, Steven, Weiland, Chase y Suárez.

Estos autores brindaron elementos para significar los entramados, los relatos entrecruzados, las complejas relaciones, las contradicciones y los recuerdos, entre otros aspectos que ayudaron

2 Las líneas de investigación del ISCEEM son: Currículum e Institución Escolar; Educación Matemática; Práctica Educativa; Formación de Docentes; Sistema Educativo del Estado de México; Política y Administración de la Educación; Historia de la Educación; Filosofía y Teoría Educativa; Educación, Sociedad y Cultura.

3 Una escuela primaria multigrado es aquella que ofrece atención pedagógica a estudiantes de distintos grados en un solo espacio, es decir, un profesor atiende a más de un grado simultáneamente en la misma aula. 
a configurar narrativas, al tiempo que dieron la posibilidad de significar, construir y reconstruir historias o sucesos del pasado.

Declaro que el marco referencial construido sobre la narrativa resultó significativo, sin embargo, la experiencia acumulada en el manejo de la etnografía y la investigación-acción resultó una herramienta determinante no sólo durante el trabajo de campo, sino también en el tratamiento de la información empírica; los análisis e interpretaciones que realicé tomaron como referencia el proceder etnográfico en la reconstrucción de los retratos narrativos.

\subsubsection{Caminar para encontrarme}

En el año 2010, cuando se integró el CA, me encontraba entrampado en un doctorado que había iniciado cuatro años atrás; por distintas circunstancias no lograba culminar con el proceso para la obtención del grado, entonces me invitaron a participar en el cuerpo académico y no dudé en incorporarme, conocía a los investigadores que lo integrarían, sabía de su profesionalismo, compromiso y trabajo. En la segunda mitad de la década de los noventa, participamos en una comisión encargada de la evaluación del plan de estudios de la Maestría en Ciencias de la Educación del ISCEEM, actividad que me permitió conocer la forma de trabajo, posicionamiento, experiencias y apuestas académicas de cada integrante.

En el inicio de las actividades del CA no dimensioné las implicaciones que esto representaba: cambio de objeto de estudio, desplazamiento a otras líneas de investigación; nuevos marcos epistemológicos, teóricos y metodológicos; trabajo en equipo, tiempos distintos en la entrega de informes de investigación, viajes para entablar reuniones; asistencias a eventos relacionados con la temática de estudio; construcción de relaciones con grupos e investigadores afines al cuerpo académico.

En esta historia hay un aspecto que resultó muy formativo: el reconocerme implicado con lo que comenzaba a investigar. Heller (2011) señala que una implicación se presenta porque hay una relación desde el sentimiento. Al incorporarme al CA comencé a experimentar una contradicción que desataba una serie de sentimientos que me vinculaban directamente con el objeto de estudio, es decir, mi situación de no obtener el grado de doctor constantemente se asomaba en cada uno de los pasos del equipo. El nombre que le dio origen al grupo: "Formación para la investigación en los posgrados en educación y la eficiencia terminal”, se convirtió en un reclamo constante sobre mi situación. En la problematización que realizamos sobre la eficiencia terminal en el posgrado estaban muy presentes cuestionamientos que se volcaban sobre mí.

Heller (2011) también plantea que la implicación es involucramiento activo, es decir, las trayectorias profesionales de los académicos del posgrado que colaboraron como informantes en la investigación, me sirvieron de espejo; al escuchar y después leer los relatos de estos académicos encontraba aspectos que no había enfrentado en mi propia formación como estudiante de un doctorado.

La primera investigación del CA arrojó información para comprender los procesos de formación de investigadores educativos, al tiempo que comenzó a tocar mi subjetividad y me motivó a profundizar en aspectos que me ayudaron a entender mis procesos. En el libro "Formación para 
la Investigación en los Posgrados en Educación. Perfiles, Trayectorias, Experiencias y Saberes”, escribí el capítulo titulado "Trayectorias académicas y profesionales de docentes investigadores en el posgrado en educación”. En este analicé las relaciones académicas en las trayectorias profesionales de los investigadores del estudio, caractericé la manera en que los académicos se relacionan con los estudiantes del posgrado, la forma en que han configurado la tutoría y la dirección de tesis.

En las narrativas de los informantes y en algunos textos, como los de Moreno (2010), encontré historias parecidas a las mías; en ellas hallé procesos teñidos de humanismo y otros de angustias y pesares. Los temas principales en las relaciones académicas fueron: el humanismo, el reconocimiento del otro, la horizontalidad, las mediaciones institucionales, el trabajo, la sistematicidad y el orden. El análisis de estos aspectos, me permitió mirar lo que había vivido no sólo en el posgrado, sino además en mi historia personal, varias condiciones que son necesarias en la construcción de una relación académica no se cumplieron en mi proceso.

En el programa doctoral que cursaba había atendido la mayoría de los requisitos académicos para obtener el grado: entrega de avances parciales, tesis prácticamente terminada (me encontraba construyendo un apartado final y en revisión final del trabajo), presentaciones de avances ante el comité tutorial (faltó una, previa a la sustentación), estancia académica en el extranjero, artículo académico para su publicación (se encontraba en revisión); sin embargo, el aspecto que no logró llegar a buen puerto fue una relación académica que impulsara el desarrollo y culminación del proceso formativo. Lo que encontré en mí transitar fue una lucha de poder, una ponderación del ego por parte del tutor, un ambiente vertical, desconocimiento y desvaloración del otro.

En algún momento, cuando relataba esta situación, se me cuestionó el motivo por el cual no intenté cambiar la relación, por qué no defendí mi proceso y producción ante el tutor; la respuesta fue sencilla, pero muy dolorosa, no estaba preparado para defenderme; parece inaudito, a estas alturas de mi vida profesional todavía pesaba la imagen autoritaria del otro, imagen que desde la infancia en el seno familiar me fue inculcada y que las instituciones educativas fomentaron. El orden, el trabajo, el sometimiento, el silencio, el miedo, el desconocimiento del otro, entre otros aspectos, brincaron en el espejo de las narrativas escuchadas y leídas. Con el trabajo de investigación en el CA logré comprender que existen situaciones que se entrecruzan y determinan el tipo de formación o producción en los posgrados, una de ellas es el tipo de relación que se construye, la cual dependerá de varias condiciones.

Considero que la formación para la investigación es un proceso complejo y multideterminado, coloco el énfasis en las relaciones académicas porque ese aspecto fue el que se activó en mi sentir personal. Con los referentes epistemológicos, metodológicos y teóricos del CA, logré comprender-me en esta situación, reconstruir-me en ese aspecto y retomar el rumbo en la concreción de la obtención del grado.

Un viraje alcanzado con el CA fue el caminar acompañado, después de una serie de experiencias sobre la investigación en solitario, ahora los pasos se compartirían con otros. En 1995, cuando me incorporé a la División Académica Tejupilco del ISCEEM, sólo existían tres académicos de tiempo completo y dos contratados por horas. Cada uno estaba ubicado en una línea de investigación distinta, la de práctica educativa fue en la que realicé mis primeras investigaciones, in- 
cluyendo las que me permitieron la obtención del grado de maestro y estudios de doctorado, las cuales desarrollé de manera individual y al inicio en solitario. Con la integración del CA en 2010, los procesos se desarrollaron en equipo y los tiempos y ritmos de la investigación se orientaron por las dinámicas del Prodep y del Instituto.

Las estrategias de trabajo, los compromisos, los acuerdos, el desarrollo de tareas, las movilizaciones a Ecatepec, Tejupilco, Toluca y otros lugares fuera de nuestra entidad, la lectura y la escritura, entre otras actividades y procesos, movilizaron en cada uno de nosotros una serie de habilidades y valores no exploradas con anterioridad, por ejemplo, la tolerancia a las particularidades del otro (cabe mencionar que nuestros perfiles profesionales son distintos: pedagogo, antropólogo y educadores), el diálogo en la mediación de toma de decisiones, la solidaridad más allá de los compromisos académicos, el reconocimiento del liderazgo del responsable del CA, la disposición a la escucha, el compartirse en las historias personales, académicas, discursivas y marcos teórico-metodológicos.

Con lo antes dicho, puedo asegurar que con el paso del tiempo y el desarrollo del CA hemos logrado una consolidación como equipo o comunidad de investigación; ahora entramos a una nueva etapa de evolución, más allá del reconocimiento del Prodep, nos encaminamos en interacción con otros cuerpos académicos o redes de investigación.

\subsection{Experiencias, tensiones y saberes excluidos de los procesos de evaluación de los cuerpos académicos}

David Pérez Arenas

El registro y permanencia de todos los cuerpos académicos que aspiran a ingresar, mantener o cambiar su estatus ante el Prodep, están sujetos a un proceso de evaluación, con el propósito de valorar los avances y logros obtenidos en función de los criterios definidos para cada uno de los niveles a los que estos pretendan llegar; los criterios se definen en las “Reglas de Operación” que se emiten cada año y valoran lo que se considera da cuenta de la productividad del trabajo del personal académico de tiempo completo a partir de cuatro vertientes: docencia (seminarios impartidos), investigación (proyectos concluidos y publicados), tutorías (estudiantes atendidos y tesistas graduados) y gestión académica (comisiones, dictámenes, diseño de planes de estudio, entre otros).

Tanto los criterios como los procedimientos de evaluación para decidir si se otorga o no el registro a un CA, si se le autoriza o no el cambio al nivel solicitado, en una primera lectura parecieran ser claros, coherentes y precisos, sin otro propósito más que promover el trabajo colegiado en las instituciones de educación superior, con la intención de apoyar la profesionalización del personal académico de las IES y el desarrollo de la investigación educativa; sin embargo, estos terminan por reducir la evaluación a una rendición de cuentas, a partir sólo de los productos sin considerar los procesos, mucho menos las experiencias y tensiones que en estos se generan.

Al respecto, me permitiré compartir algunas reflexiones derivadas de las experiencias que como responsable del CA he vivido en relación con los procesos de evaluación, resultado de las actividades realizadas con los proyectos trabajados, a partir de un diálogo crítico y reflexivo que 
permita dar cuenta tanto de las tensiones que como colectivo hemos enfrentado en estos procesos, así como de las posibilidades que dichos programas nos han ofrecido para el trabajo colegiado, orientado al desarrollo de la investigación y a nuestros propios procesos de formación profesional relacionada con este campo.

Desde septiembre de 2010, cuando el Prodep nos otorgó el reconocimiento de "Cuerpo Académico en Formación”, a la fecha, marzo de 2020, nos hemos sometido a dos procesos de evaluación para solicitar nuestro cambio a "Cuerpo Académico en Consolidación”, en 2013 y 2016, lográndolo hasta el segundo intento, y en 2019 para el cambio a "Cuerpo Académico Consolidado"; los usos y efectos que han tenido estos procesos tanto en la dirección y administración como entre los compañeros académicos del ISCEEM, han sido variables y extremos, dependiendo de los resultados obtenidos: aceptado, permanecer, cambiar de nivel o retirarle el reconocimiento ante el programa; desde la congratulación, orgullo y uso para la acreditación institucional, hasta los de cuestionamiento, descalificación y desdén por todos ellos.

¿Cuál es el balance que puedo hacer de diez años de liderar un CA en cuanto a las experiencias que me dejaron estos procesos de evaluación y que paradójicamente han sido excluidas? Al igual que en el primer proyecto del CA, cuando hago alusión a las experiencias, no me refiero a los acontecimientos vividos o acumulados, como comúnmente se dice cuando se afirma que esta se obtiene con el paso de los años, sino a los acontecimientos que nos permiten reconstruirnos, narrarnos, formarnos y transformarnos al articular nuestras vivencias con los sentidos que le damos a nuestra vida y los significados que construimos en torno a ellas, a la manera en que vivimos, habitamos y pasamos por el mundo tal como lo refiere Larrosa (2006).

De manera que las experiencias asociadas con el cuerpo académico, al paso del tiempo, me permiten sostener que el trabajo colegiado es una de las posibilidades que nos ofrecen estos programas, pero vivida con muchas tensiones, sobre todo cuando las instituciones de educación superior, como el ISCEEM, se caracterizan por moverse entre la marginalidad que les dota el no ser ni una universidad ni una institución formadora de docentes como las normales, sino un instituto "sui géneris" que ofrece posgrados para el magisterio y realiza investigación, pero en una condición adversa por su dependencia de la administración central, una ausencia de financiamiento y consecuente escasez de recursos para la investigación, la subordinación de las funciones sustantivas a la lógica administrativa y la endogamia institucional que lo caracteriza.

En este contexto también valoro la gestión por parte del Instituto para que, en 2010, la institución tuviera la posibilidad de participar en las convocatorias de los CA, lo que resultó un intersticio para la investigación, por lo que me decidí convocar a compañeros que, luego de mi experiencia al trabajar con ellos, podía asegurar tenían conocimiento e interés en los procesos de formación para la investigación y su incidencia en la eficiencia terminal de los posgrados, además por supuesto del compromiso institucional.

Casi de manera inmediata al registro, antes de que lográramos comprender las implicaciones del trabajo en un CA, salió la convocatoria para financiamiento de investigaciones; hicimos el registro, logramos que nuestro proyecto fuera evaluado favorablemente y se nos otorgara $60 \%$ del recurso solicitado; todo ello tan rápido que fue mayor la emoción por el logro obtenido, que la reflexión sobre los problemas e implicaciones que esto tenía, una de las más comunes, el des- 
fase de la lógica de los tiempos académicos con los tiempos burocráticos y más con los políticos; en esto no opera el rigor con el que se definen los indicadores y se evalúa. En fin, sabíamos que contábamos con un recurso, pero no cuándo nos lo iban a proporcionar, aunque sí existía la obligación de desarrollar, concluir un proyecto y entregar el informe; había mucha presión, pero también emoción y más aún, múltiples experiencias derivadas del proyecto de investigación y del trabajo colegiado.

Las vivencias tenían que ver con el hecho de haber tomado como objeto de estudio a los compañeros del ISCEEM que más experiencias tenían en relación con la tutoría para la elaboración de tesis al contar con más graduados en la maestría, lo que nos dio la oportunidad de reconocer dos aspectos: la riqueza de experiencias y saberes que estos habían acumulado en relación con la metodología y didáctica de la investigación en el posgrado, y el aislamiento con el que desarrollábamos el trabajo académico; eran compañeros a quienes conocíamos de muchos años en el Instituto, con quienes habíamos convivido a diario, en ocasiones compartiendo el cubículo o el trabajo en una comisión; sin embargo, no habíamos tenido la oportunidad de contar con un espacio donde intercambiar nuestras experiencias académicas en un sentido amplio, es decir, incluyendo miedos, temores, problemas y errores que habíamos cometido en la difícil tarea ya no de enseñar o formar, sino de introducir a los maestrantes al oficio de la investigación, y por supuesto, las experiencias gratificantes que nos dieron seguridad y resultados, pero sobre todo, que nos dotaron de una autoridad académica en la formación para la investigación.

Lo anterior representaba un mensaje y corroboraba una situación: la ausencia del trabajo académico colegiado en una institución que entre sus objetivos y programas lo promovía como elemento sustantivo, pero lo real, era la soledad en que comúnmente se trabaja dentro de las instituciones, bien sea por el temor a mostrar nuestros errores y deficiencias o por arrogancia académica. Por lo pronto, el proyecto había abierto una puerta y posibilidad para el trabajo colegiado institucional.

Aunado a todo esto, la posibilidad del trabajo tanto con los propios integrantes del CA como con colegas de otras instituciones se fue diversificando y ampliando a partir de las numerosas e interminables reuniones destinadas no sólo a organizar y desarrollar las actividades, sino también para el análisis de la información e integración de los informes, en las que los tiempos reales rebasaban siempre los tiempos institucionales, y donde las fronteras entre los temas o discusiones académicas e institucionales, y las personales, familiares o sociales se diluían cada vez más, al igual que las horas y espacios en que se realizaban, pues podían darse en una de las salas del ISCEEM en los tiempos programados, en la sobremesa de la comida o a altas horas de la noche en el bar o habitaciones del hotel.

Las experiencias compartidas en estos espacios corroboraban uno de los supuestos que sostenía el proyecto: el ejercicio del oficio y la formación para la investigación están entrecruzados por una multiplicidad de saberes provenientes de diferentes ámbitos, como el existencial y el experiencial, de manera que, como dice Tardif (2009), no sólo enseñamos o investigamos con la cabeza, sino también con el corazón, y, agregamos, a veces con el hígado.

Hubo muchos aprendizajes y experiencias durante los tres primeros años (que parece mucho tiempo), pero en una dinámica institucional con una obsesión por la administración de sus fun- 
ciones sustantivas, el tiempo se va en un abrir y cerrar de ojos, cuando te das cuenta ya tienes que estar llenando los formatos para la evaluación del CA, con la esperanza y el imaginario de transitar al siguiente nivel; en nuestra primer evaluación, dado que había sido un periodo de trabajo intenso y-creíamos-con mucha producción, teníamos la seguridad de que lo lograríamos. ¡No fue así, el golpe fue fuerte!

Lo real emergía, en tres años más nuevamente seríamos evaluados, y entre los criterios definidos en la convocatoria para el paso a "Cuerpo Académico en Consolidación”, además de las funciones de investigación, docencia, tutoría y gestión académica, se requería del trabajo con otros CA, grupos o redes de investigación, por lo que nos dimos a la tarea de buscar los contactos e iniciar el trabajo colegiado en otros tiempos y espacios.

Fue así como la difusión de los avances e informes del proyecto nos dieron la oportunidad de interlocución con otros investigadores, vale la pena destacar la de Daniel Saur, de la Universidad de Córdoba, Argentina, con quien compartíamos el interés en relación con el objeto de estudio, y quien amablemente nos orientó para evitar algunos sesgos en el análisis de los resultados; no puedo dejar de mencionar la importancia de la participación de Guadalupe Moreno Bayardo, tanto para el trabajo de campo como para el prólogo y comentario del libro, una de las investigadoras con mayor autoridad académica en la formación para la investigación en los posgrados en Educación en México.

Estas actividades nos dieron también la posibilidad de integrarnos a las Redes de Posgrados en Educación A. C. y de Investigadores de la Investigación Educativa en México, a través de los seminarios, proyectos, congresos y foros de investigación realizados, que nos permitieron la interlocución con compañeros de otras instituciones interesadas en la formación para la investigación en los posgrados, espacios que sin duda abonaron al nuevo proyecto del $\mathrm{CA}$, pero sobre todo ampliaron el espectro del trabajo colegiado.

Estas actividades y los productos del proyecto nos permitieron, después de participar en el segundo periodo de evaluación (ahora más con el temor que con la esperanza de pasar al siguiente nivel), para nuestra sorpresa, lograr el cambio a "Cuerpo Académico en Consolidación" en 2016; no obstante, con todo y que las condiciones institucionales para el trabajo colegiado fueron muy adversas, el ánimo y la emoción se antepusieron, así que nos llevaron a buscar y demandar nuevamente su mejoramiento a partir de un diálogo con la dirección del Instituto, a quien debemos reconocer que nos había escuchado y autorizado algunos apoyos para el trabajo; así que en la nueva reunión teníamos las reglas de operación en la mano, con demandas concretas y precisas en cuanto a tiempos y condiciones para el trabajo colegiado.

Logramos la escucha, comprensión y autorización a la mayor parte de planteamientos, eso no lo podemos discutir; sin embargo, el dispositivo de control administrativo que, de manera silenciosa y casi imperceptible se fue generando en los últimos años del Instituto, se encargó no sólo de echar abajo todos los acuerdos o acciones orientadas a la promoción del trabajo académico, sino en ocasiones, de establecer acciones persecutorias a grados extremos o perversos. Una de las explicaciones que podemos dar a lo anterior, es la fragmentación de funciones de una institución donde el personal con nombramiento de investigador, pero con funciones administrativas, es casi similar al académico, y que la mayoría de los primeros no realicen funciones sustantivas, por lo que se limitan a la administración de la docencia y la investigación. 
Finalmente, a manera de cierre y en el contexto de espera de resultados de la última evaluación de 2019, podemos decir después de casi diez años de trabajo colegiado en el CA, que este ha sido un espacio de formación a manera de un caleidoscopio, con sus claroscuros, brillos, opacidades y matices inimaginables para quienes hemos formado parte de él y para la propia institución; ha sido una posibilidad de experimentar nuevas formas de trabajo e interlocución, tanto para la producción y difusión de conocimiento como para la formación de investigadores, al tiempo que hemos enfrentado muchas limitaciones y tensiones que habría que analizar y valorar a partir de los resultados de las evaluaciones a este y otros CA de la institución, reducidos por lo general al cumplimiento de estándares orientados por la productividad.

En relación con los comentarios de los compañeros, cuando nos veían apurados y angustiados elaborando los informes o desarrollando las actividades, nos decían: "Pero querían estar ahí, ¿no? ¡Yo por eso no participo en esas convocatorias! A ustedes que les gusta complicarse la vida”, por decirlo de manera suave y directa. A veces, llegamos a pensar que tenían razón, pero cuando los vemos en su soledad, rumiando sus fracasos, empantanados en la endogamia institucional; y como contraparte, hacemos memoria de los intercambios, discusiones y producción derivada del trabajo colegiado del CA, sumando a compañeros de otras instituciones, creemos que la aventura ha valido la pena.

\section{A MANERA DE CONCLUSIONES}

Durante estos primeros casi diez años de trabajo del CA, sus integrantes, en varias ocasiones, hemos reflexionado y comentado sobre las implicaciones, posibilidades y limitaciones que ha tenido este colectivo, desde la integración hasta el trabajo y la producción de conocimiento colegiado; sin embargo, no nos habíamos dado la oportunidad de hacer una valoración, a partir de nuestras narrativas, sobre lo que este espacio de formación había representado para cada uno, así como el lugar que este tipo de programas ocupan para la vida académica de una institución como el ISCEEM, incluyendo por supuesto las peripecias, tensiones y problemáticas que en diferentes sentidos se tienen que sortear.

Resulta necesario e importante el análisis realizado en este escrito a partir de la articulación entre el contexto en que surgen estos programas y su trayectoria institucional, así como de las experiencias y saberes de quienes han formado parte de uno de los CA integrados desde la primera convocatoria, para lograr una valoración más global no sólo de los resultados, posibilidades y limitaciones que enfrentan este tipo de programas en las instituciones orientadas a la formación de docentes, investigadores y producción del conocimiento, como el ISCEEM, sino también para tomarse como un punto de referencia en relación con el lugar que el trabajo colegiado ocupa en las funciones y políticas de estas instituciones, pero sobre todo, para tomar decisiones asociadas con la proyección o visión para el futuro de su vida académica institucional.

Como lo hemos mostrado, han sido muchos los logros y aciertos vinculados con la formación para la investigación y producción de conocimiento que de manera individual y colectiva, personal e institucional, nos ha dejado el participar en un CA, a partir no sólo de los productos obtenidos (capítulos de libro, ponencias, graduados), sino además de las experiencias derivadas del trabajo en equipo, del intercambio con otros investigadores y sus redes; también han sido 
muchos los contratiempos, obstáculos, problemas y sinsabores que hemos tenido que sortear para mantener el registro y continuar con el trabajo.

En este sentido, es importante destacar que las experiencias derivadas del trabajo colegiado en el CA, nos permitieron no solo acumular saberes, en relación con la formación para la investigación y la producción de conocimiento, sino habitar el mundo del ISCEEM y de la investigación educativa; pero sobre todo narrarnos, reconstruirnos y transformarnos como investigadores, como docentes y como personas, tal y como lo señala Larrosa (1998); bien sea para prolongar la mirada o para incorporar y entretejer las subjetividades e implicaciones derivadas de los proyectos profesionales personales, con los programas institucionales, como el de PRODE, como lo expresó Hernández.

Experiencias mediadas por una ética del reconocimiento de los otros, sean estos los integrantes del CA, la Institución o los estudiantes a quienes se está formando para la investigación, como lo planteo Condés; el trabajo colegiado, sobre todo cuando está mediado por las tensiones institucionales, requiere además del trabajo y compromiso personal, de un liderazgo académico, del diálogo y colaboración, la confianza y escucha de los otros.

Atilano, refiere que estas experiencias, como una posibilidad de encuentro no sólo con los otros, sino como un camino para encontrarse a sí mismo, para vivir, habitar el mundo y darle un sentido a nuestra vida, tal y como lo planteó Larrosa (2006); a partir del reconocimiento de nuestra implicación con nuestros propios objetos de estudio, lo que en ocasiones resulta doloroso por los adeudos en las trayectorias personales y profesionales, pero necesario en los procesos de formación para la investigación.

No obstante, este tipo de experiencias dice Pérez, se convierten en intersticios y acontecimientos que nos permiten reconstruirnos y resolver las tensiones generadas entre las diferentes dimensiones y tiempos en que se desarrolla la producción de conocimiento, sobre todo en instituciones donde se contrapone la lógica burocrática administrativa a la lógica académica de la investigación.

De esta manera, la dimensión institucional es una de las instancias, donde consideramos no sólo se generan el mayor número de tensiones, sino las más agudas, al intentar hacer equivalente la lógica y los tiempos administrativos y políticos, con el trabajo, los tiempos y la lógica académica que requiere la producción de conocimiento y la formación para la investigación; mediado y agudizado todo eso además por la escasa promoción de espacios y estrategias institucionales para el trabajo colegiado, el desplazamiento de la investigación como función sustantiva del instituto y una preocupación mayor por el control y administración de la misma, que por la producción de conocimiento y la formación de investigadores.

No obstante, lo adverso de las condiciones en que se desarrollan estas funciones sustantivas de las IES como el ISCEEM, coincidimos en reconocer que el trabajo colegiado derivado de los programas institucionales como PRODEP, se convirtió en un intersticio y en una posibilidad tanto para el reconocimiento, reencuentro, crecimiento y transformación de los procesos de formación personales y profesionales en relación con la investigación; pero mediados siempre por una serie de tensiones que se tuvieron o tienen que ir resolviendo conforme se van presentando, 
al tiempo que se van generando un conjunto de saberes producto de las experiencias y vivencias que se adquieren en el transcurrir de la vida cotidiana, pero que se convierten como tales, en el momento que emergen y se clarifican a través de la reflexión y el análisis, mediado por la conciencia y el pensamiento crítico de quienes las vivieron.

Emergen así, saberes asociados tanto con las estrategias asociadas con el trabajo colegiado como la disciplina, el diálogo, el compromiso y la escucha, como las relacionadas con los propios procesos de formación y ruptura con las concepciones personales, como el desplazamiento de las líneas o temáticas de investigación iniciales, el trabajo sistemático, la ruptura con las propias convicciones, miedos y temores que arrastramos en nuestras historias personales.

Todo esto nos llevó a recocer a la formación para la investigación, como ese proceso complejo y multi o mejor dicho sobredeterminado por una diversidad de factores, condiciones y elementos, pero direccionados por uno de ellos, si no de manera fija, si temporal; al tiempo que los CA como espacios para la promoción o formación de la investigación, se configuran en caleidoscopios con una diversidad de luces, matices, opacidades y claroscuros, dependientes de la interacción entre las dinámicas institucionales y los posicionamientos de los integrantes de estos colectivos académicos.

Por tales razones, consideramos que es necesario sumar a este balance del trabajo del CA, una evaluación institucional con la participación de la dirección, administración, personal académico y órganos colegiados del Instituto, en cuanto al lugar e importancia que se pretenda otorgar a esos programas y espacios de formación para la investigación y producción de conocimiento; para con base en ella, tomar decisiones, definir propósitos y estrategias que permitan potenciar y apoyar el trabajo individual y colegiado de los docentes investigadores del Instituto, en caso de que la valoración sea positiva y se tome la decisión de continuar con el desarrollo de este tipo de programas u otros orientados a tales fines.

Lo anterior no implica el reconocimiento e importancia que tiene un ejercicio como el realizado hasta ahora para abrir espacios de diálogo e interlocución con otros académicos, grupos o redes de investigación de distintas instituciones y países, interesados en los problemas y temas compartidos a partir de las experiencias, saberes y tensiones que un CA adquirió o enfrentó en el trabajo colegiado asociado, en este caso, con la producción de conocimiento y formación para la investigación en los posgrados en Educación.

\section{REFERENCIAS}

Althusser, L. (1967). La revolución teórica de Marx. México: Siglo XXI.

Bolivar, A., Domingo, J. y Fernández, M. (2001). La investigación biográfico-narrativa en educación. Enfoque $y$ metodología. Madrid: La Muralla.

Chase, S. (2015). Investigación narrativa. Multiplicidad de enfoques, perspectivas y voces. En N. E. Denzin (2015). Métodos de recolección y análisis de datos (pp. 58-112). México: Gedisa.

De Alba, A. (2017) Entrevista a Ernesto Laclau. En A. De Alba y M. Peters (2017). (Coords.). Sujetos en proceso: diversidad, movilidady políticas de subjetividad en el siglo XXI (p. 291), México: IISUE educación 


\section{E X P E R I E N C I A S}

Díaz-Barriga, A. (2009). Un sistema de acreditación que desconoce su pertinencia social. En A. DíazBarriga (2009). El posgrado en educación en México (pp. 45-88). México: IISUE-UNAM.

Heller, A. (2011). La teoría de los sentimientos. México: Coyoacan.

Huberman, M., Thompson, Ch. L. y Weiland, S. (2000). Perspectiva de la carrera del profesor. En J. B. Bidle, La enseñanza y los profesores I. La profesión de enseñar. Barcelona: Paidós.

ISCEEM. (2011). Programa de Maestría en Investigación de la Educación. Gaceta ISCEEM (38), 1-45.

Laclau, E. (2006). The Homesteead, Evanston. (A. De Alba, Entrevistador) Illinois, Chigago, Estados Unidos.

Larrosa, J. (2006). Sobre la experiencia. Revista Aloma, Filosofía de l'educacio i de l'esport Banquema, 19, 87-11. [Recuperado de https://www.raco.cat/index.php/Aloma/article/view/103367]

Larrosa, J. (1998). Sobre la experiencia. Universidad de Barcelona. Aloma.

Lyotard, J. F. (1993). La condición posmoderna. España: Planeta Agostini.

Medina, P. (2000). ¿Eres maestro normalistaa y/o universitario? La docencia cuestionada. México: Plaza y Valdés.

Moreno, G. (2010). Historias de formación para la investigación en doctorados en educación. México: Plaza y Valdés.

Moreno, G. et al. (2009). La formación de investigadores en educación: cuatro acercamientos al estado de conocimiento. Guadalajara, México: Universidad de Guadalajara.

Ortega, C., \& Hernández, A. (2016). La conformación del cuerpo académico en la escuela normal, un medio para mejora en la formación docente. Ra Ximhai, 12(6), 295-303 [Recuperado de: https:// www.redalyc.org/articulo.oa?id=46148194020]

Pérez, D., Atilano, P. y Condés, F. (2017). Formación para la investigación en los posgrados en educación. Perfiles, trayectorias, experiencias y saberes. Toluca, México: ISCEEM.

Ricoeur, P. (1995). Tiempo y narración (Vol. I). México: Siglo XXI.

Sánchez, R. (2010). Enseñar a investigar. Una didáctica nueva de la investigación en ciencias sociales y humanas. México: IISUE-UNAM.

SEP. (2020). Apoyo para el fortalecimiento de Cuerpos Académicos. Diario Oficial, 10 enero 2020. [Recuperado el 15 de marzo de 2020 de: http://www.dgesu.ses.sep.gob.mx/prodep.htm]

Serrano, J. A. y Ramos. J. M. (2011). Trayectorias biográficas y prácticas. México: UPN.

Tardif, M. (2009). Los saberes del docente y su desarrollo profesional. España: Narcea.

Yuren, T. (2005). Ethos y autorformación del docente. Análisis de dispositivos de formación de profesores. México: Cerezo.

Zemelman, H. (1987). Conocimiento y sujetos sociales. México: Colmex.

Zemelman, H. (2009). Reflexiones entre epistemología y método. México: Cerezo. 